\title{
Pengembangan Sistem Informasi Geografis Berbasis Android Pada Wisata Daerah Lombok, Nusa Tenggara Barat
}

\author{
Ahmad Subki ${ }^{1}$, Bahtiar Imran ${ }^{2}$, Surni Erniwati ${ }^{3}$ \\ 1 Program Studi Rekayasa Perangkat Lunak, Universitas Teknologi Mataram \\ 2,3Program Studi Rekayasa Sistem Komputer, Universitas Teknologi Mataram \\ *bahtiarimranlombok@gmail.com
}

\begin{abstract}
Abstrak
Pulau Lombok merupakan salah satu daerah tujuan wisata di Indonesia yang memiliki potensi untuk dikembangkan. Berdasarkan data dari Dinas Pariwisata Provinsi NTB pada akhir 2019, jumlah kunjungan wisatawan sebanyak 3.706.352 wisatawan, dengan rincian 1.550.751 wisatawan mancanegara dan 2.155.561 wisatawan nusantara. Berdasarkan Rencana Strategis 2018-2023 Dinas Kebudayaan dan Pariwisata Provinsi Nusa Tenggara Barat pulau lombok memiliki objek wisata yang potensial seperti wisata pantai, air terjun, pegunungan, kuliner, budaya, agama, dan lain-lain. Namun tidak semua objek wisata yang ada diketahui oleh para wisatawan yang berkunjung, baik lokasi tempat wisata ataupun jarak yang ditempuh ke lokasi wisata, sehingga perlu adanya upaya untuk meningkatkan jumlah pengunjung yang datang ke pulau Lombok melalui berbagai upaya. Salah satu upaya yang dapat dilakukan yaitu penerapan sistem pariwisata berbasis Android agar dapat diakses oleh wisatawan mancanegara atau wisatawan nusantara yang dapat memberikan informasi lengkap tentang informasi wisata yang ada di Pulau Lombok. Metode pengembangan sistem yang digunakan dalam penelitian ini adalah metode Reseach and Development (R\&D). Sistem Informasi Geografis dengan metode Reseach and Development (R\&D) dapat memberikan hasil yang baik dan dibuktikan dari hasil pengujian terbatas mendapatkan hasil rata-rata $71,45 \%$ dengan kriteria "BAIK", dan pengujian lapangan dengan mendapatkan hasil dengan rata-rata $72,32 \%$ dengan kriteria "BAIK".
\end{abstract}

Kata kunci: Android, Reseach and Development (R\&D), Sistem Informasi Geografis, Wisata

\begin{abstract}
Lombok Island is one of the tourist destinations in Indonesia that has the potential to be developed. Based on data from the NTB Provincial Tourism Office at the end of 2019, the number of tourist visits was $3,706,352$ tourists, with details of 1,550,751 foreign tourists and 2,155,561 domestic tourists. Based on the 2018-2023 Strategic Plan, the Culture and Tourism Office of West Nusa Tenggara Province, the island of Lombok has potential tourism objects such as beach tourism, waterfalls, mountains, culinary, culture, religion, and others. However, not all existing tourist attractions are known by visiting tourists, both the location of tourist attractions or the distance traveled to tourist sites, so it is necessary to make efforts to increase the number of visitors who come to the island of Lombok through various efforts. One of the efforts that can be done is the application of an Android-based tourism system so that it can be accessed by foreign tourists or domestic tourists who can provide complete information about tourist information on the island of Lombok. The system development method used in this research is the Research and Development (R\&D) method. Geographic Information Systems with the Research and Development (R\&D) method can provide good results and can be proven from the limited test results getting an average result of $71.45 \%$ with "GOOD" criteria, and field testing with an average result of 72.32 $\%$ with "GOOD" Criteria.
\end{abstract}

Keywords: Android, Geographic Information Systems, Reseach and Development (R\&D), Tourism 


\section{Pendahuluan}

Revolusi era industri 4.0 merupakan awal dari perubahan dunia yang sangat pesat perkembangannya khususnya di bidang teknologi informasi. Dengan adanya perubahan ini mengakibatkan berubahnya cara berpikir manusia dan cara hidup [1]. Dengan adanya perubahan teknologi ini dapat menimbulkan fenomena pergeseran budaya dari sistem manual menjadi terkomputerisasi dan visual, seperti pada sektor pariwisata, terutama wisatawan Indonesia yang merupakan generasi milenial [2]. Pulau Lombok merupakan salah satu daerah tujuan wisata di Indonesia yang memiliki potensi untuk dikembangkan. Daya tarik pariwisata di Pulau Lombok berupa pemandangan alam, pantai, wisata bahari, wisata bawah laut, keagamaan, dan peninggalan kebudayaan sebagaimana yang tercantum pada Rencana Strategis 2014-2018 Dinas Kebudayaan dan Pariwisata Provinsi Nusa Tenggara Barat [3].

Berdasarkan data yang dikeluarkan oleh Dinas Pariwisata Nusa Tenggara Barat pada akhir tahun 2019, jumlah kunjungan wisatawan sebanyak 3.706.352 wisatawan, dengan rincian 1.550 .751 wisatawan mancanegara dan 2.155.561 wisatawan nusantara. Selain itu pada data Rencana Strategis tahun 2018-2023 Dinas Kebudayaan dan Pariwisata Provinsi Nusa Tenggara Barat pulau lombok memiliki objek wisata yang potensial seperti wisata pantai, air terjun, pegunungan, kuliner, budaya, agama, dan lain-lain [3]. Namun tidak semua objek wisata yang ada diketahui oleh para wisatawan yang berkunjung, baik lokasi tempat wisata ataupun jarak yang ditempuh ke lokasi wisata, sehingga perlu adanya upaya untuk meningkatkan jumlah pengunjung yang datang ke pulau lombok melalui berbagai upaya. Salah satu upaya yang dapat dilakukan yaitu dengan membuat sistem pariwisata berbasis Android. Sistem Android memiliki berbagai kelebihan dibandingkan dengan sistem informasi pariwisata berbasis web, salah satu kelebihan dari sistem Android adalah dapat diakses dengan mudah melalui Google Playstore, dan dapat di akses melalui Smartphone dengan sangat mudah, sehingga dengan membuat sistem Android pada website pariwisata ini diharapkan wisatawan tidak lagi kesulitan untuk mengetahui informasi tentang lokasi wisata yang ingin dikunjungi.

Beberapa penelitian yang telah dilakukan dalam mengembangkan pariwisata di Lombok diantaranya E-Tourism [3], Sistem Informasi Geografis berbasis web objek wisata Lombok [4], sistem informasi wisata Lombok berbasis Mobile [5], Sistem Informasi Geografis wisata kuliner [6] dan dan sistem informasi pariwisata pantai berbasis web [7]. Dari penelitian yang telah dilakukan sebelumnya sebagian besar membahas mengenai informasi-informasi 
tentang pariwisata-pariwisata yang ada di Lombok. Akan tetapi pada penelitian ini, penerapan Sistem Informasi Geografis pada objek wisata yang ada dipulau Lombok berbasis Android. Pada aplikasi yang diusulkan lebih kepada tampilan yang User Friendly, User Experience, peta lokasi yang akurat, dan pengujian lapangan yang dilakukan secara real. Diharapkan dengan adanya Sistem Informasi Geografis berbasis android ini dapat memudahkan wisatawan dalam mencari tempat wisata yang akurat dan mudah dalam pengaplikasiannya.

\section{Tinjauan Pustaka}

\subsection{Penelitian Terkait}

- Pada penelitian Apriani dan Pahrul Irfan tahun 2017 dengan judul "Aplikasi E-Tourism sebagai Pendukung Promosi Pariwisata di Pulau Lombok" menyimpulkan sistem yang diusulkan dapat dijadikan sebagai salah satu cara untuk mempromosikan objek wisata yang ada di Pulau Lombok dan dapat membantu wisatawan yang berkunjung di Pulau Lombok sehingga dapat meningkatkan kunjungan wisatawan di Pulau Lombok [3].

- Pada penelitian Subhan dan Rusydi Umar pada tahun 2019 dengan judul "Sistem Informasi Geografis Objek Wisata Kabupaten Lombok Barat Berbasis Web" menyimpulkan sistem informasi geografis berbasis web yang diusulkan dapat memberikan kemudahan bagi masyarakat maupun wisatawan lokal dan asing dalam menemukan objek wisata. Hasil pengujian sistem menggunakan metode Alpha Test yang ditujukan kepada masyarakat, pegawai dinas kebudayaan dan pariwisata dengan persentase sangat setuju mencapai $52,38 \%$ dan setuju mencapai 47,62\% [4].

Pada penelitian Arman Satriadi dan Ahmat Adil dengan judul "Sistem Informasi Wisata Lombok Berbasis Mobile Android" menyimpulkan Sistem yang diusulkan mampu memberikan informasi tentang wisata yang dipilihdan yang dilengkapi dengan rute perjalanan menuju wisata [5].

Pada penelitian Dewa Made Mertayasa dan Abd. Rizal Yambese pada tahun 2017 dengan judul "Sistem Informasi Pariwisata Pantai Berbasis Web Pada Dinas Pariwisata Dan Ekonomi Kreatif Kabupaten Banggai Kepulauan" menyimpulkan bahwa sistem yang diusulkan dapat mengelola data-data potensi wisata yang ada secara efektif dan efisien sehingga dapat memberikan informasi terbaru tentang pariwisata pantai yang ada di Kabupaten Banggai Kepulauan kepada masyarakat dengan cepat dan mudah [7].

- Penelitian Surni Erniwati dan Ahmad Subki pada tahun 2020 yang berjudul "Designing 
Geographic Information System Culinary Tour Location In The West Lombok Region Mobile-Based Application" menyimpulkan bahwa sistem yang diusulkan dapat mempermudah para pecinta kuliner untuk mencari kuliner lokasi pariwisata yang ada dipulau Lombok [6].

\subsection{Landasan Teori}

1. Android

Android adalah sebuah system operasi untuk perangkat mobile berbasis linux yang mencangkup sistem operasi, middleware dan aplikasi. Android sendiri menyediakan platform terbuka bagi para pengembang untuk menciptakan aplikasi sendiri yang ditanamkan pada bermacam piranti mobile [5] yang dimana android saat ini telah menjadi sistem operasi mobile terpopuler di dunia [8].

\section{Sistem Informasi Geografis}

Sistem Informasi Geografis (SIG) adalah suatu sistem informasi yang berfungsi sebagai pendukung pengambilan keputusan dalam perencanaan dan pengelolaan penggunaan lahan, sumber daya alam, lingkungan, transportasi, fasilitas kota, dan pelayanan umum lainya [4] Sistem Informasi Geografis merupakan paket yang terintegrasi yang dibuat secara khusus untuk mengolah data geografis [9] dan mampu menyimpan data dan memanipulasi informasi berdasarkan data geografis [10].

3. Pariwisata

Indonesia memiliki banyak warisan budaya dan pariwisata yang harus di dilestarikan [11]. Sektor pariwisata merupakan salah satu jenis industri baru yang mampu mempercepat pertumbuhan ekonomi dan penyediaan lapangan kerja, peningkatan penghasilan, standar hidup, serta menstimulasi sektor-sektor produktif lainnya. Pariwisata merupakan berbagai macam kegiatan wisata dan didukung dengan berbagai fasilitas serta layanan yang disediakan oleh masyarakat, pengusaha, Pemerintah, maupun Pemerintah Daerah [7]. Pariwisata merupakan kegiatan yang sangat bergantung pada sumber daya lingkungan sehingga diperlukan sebuah perencanaan yang tepat dalam pengelolaannya [12].

4. Sistem

Sistem berasal dari bahasa Latin (systēma) dan bahasa Yunani (sustēma) adalah suatu kesatuan yang terdiri komponen atau elemen yang dihubungkan bersama untuk memudahkan aliran informasi, materi atau energi untuk mencapai suatu tujuan [13].

\section{Metode Penelitian}

Metode penelitian ini menggunakan metode Reseach and Development (R\&D) yaitu metode 
penlitian yang biasanya digunakan untuk menghasilkan suatu produk tertentu dan menguji keefektifannya. Data yang digunakan pada penelitian ini bersumber dari data primer daerah wisata di pulau lombok serta data sekunder seperti buku dan artikel jurnal. Berdasarkan hasil observasi bahwa sistem memiliki kebutuhan fungsional sebagai berikut:

- Masyarakat yang mengelola lokasi atau tempat wisata dapat memasukkan, nama lokasi, garis lintang dan garis bujur dan foto tempat wisata.

- Pengguna atau user dapat melihat tempat wisata, detail lokasi melalui map, dapat mencari lokasi wisata, serta melihat fasilitas disekitar tempat wisata.

Sedangkan kebutuhan non fungsional yang diperlukan berupa:

- Ponsel Android

- $\quad$ OS Android v.4.0

- $\quad$ RAM 2GB, memori 16 GB

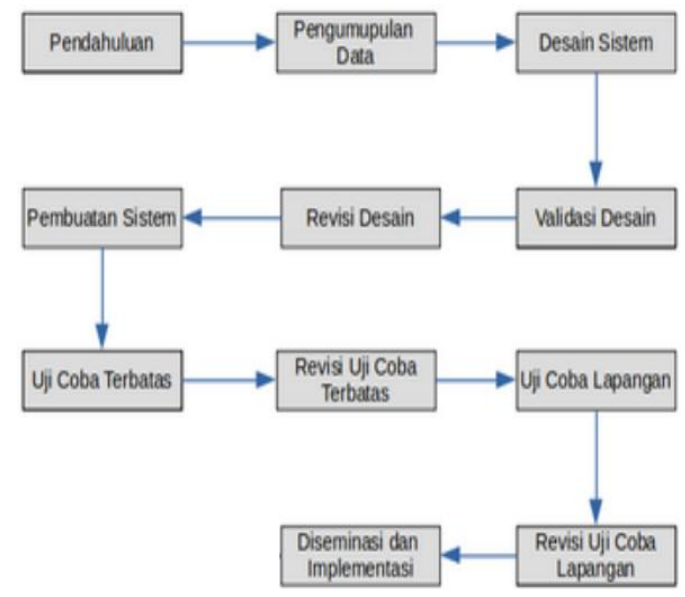

Gambar 1. Tahapan Model Penelitian R\&D
4. Hasil dan Pembahasan

\subsection{Desain Sistem}

a. Use case Diagram

Diagram use case merupakan proses pemodelan fungsi-fungsi sistem dalam konteks proses bisnis, sebuah aktor yang mengawalinya dan bagaimana sistem atau perangkat lunak tersebut merespon kondisi tersebut [3], [7]. Dalam sistem informasi geografis ini terdapat tiga ackor utama yaitu admin sistem dan user/pengguna yang memiliki hak akses dan aktifitas yang berbeda seperti yang terlihat pada Gambar 2.

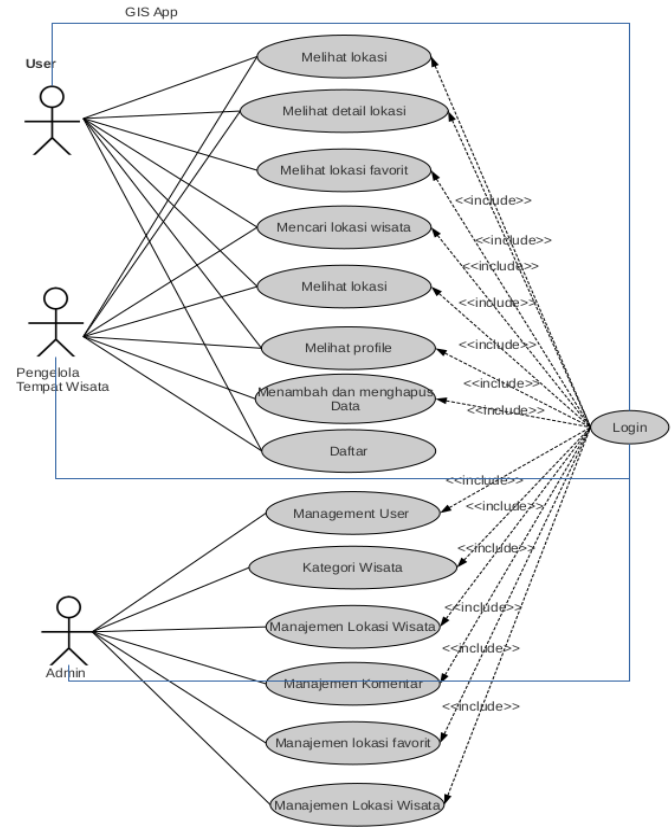

Gambar 2 Use case Diagram

b. Entity Relation Diagram (ERD)

ERD merupakan sebuah bentuk relasi antar tabel dalam sebuah database [6] yang dikembangkan berdasarkan teori himpunan untuk pemodelan basis data relasional [14]. 
Untuk penelitian ini ERD dapat dilihat pada gambar 3 berikut:

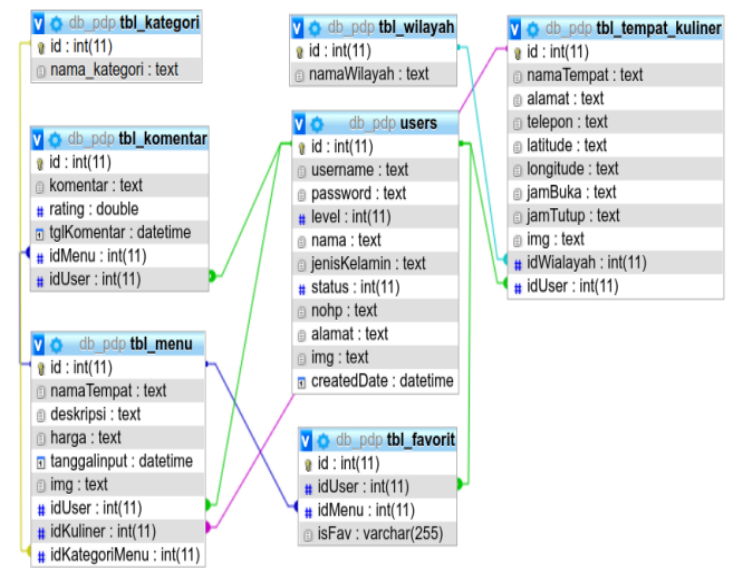

\section{Gambar 3 Entity Relation Diagram}

\section{c. Activity Diagram}

Activity diagram merupakan aktivitas yang menggambarkan berbagai aktivitas yang terdapat pada sistem yang dirancang, yakni awal dari sebuah aktivitas, decision yang mungkin terjadi dan bagaimana aktifitas tersebut berakhir [7], [15]. Pada perancangan sistem dalam penelitian ini terdiri dari beberapa activity seperti gambar 4. berikut:

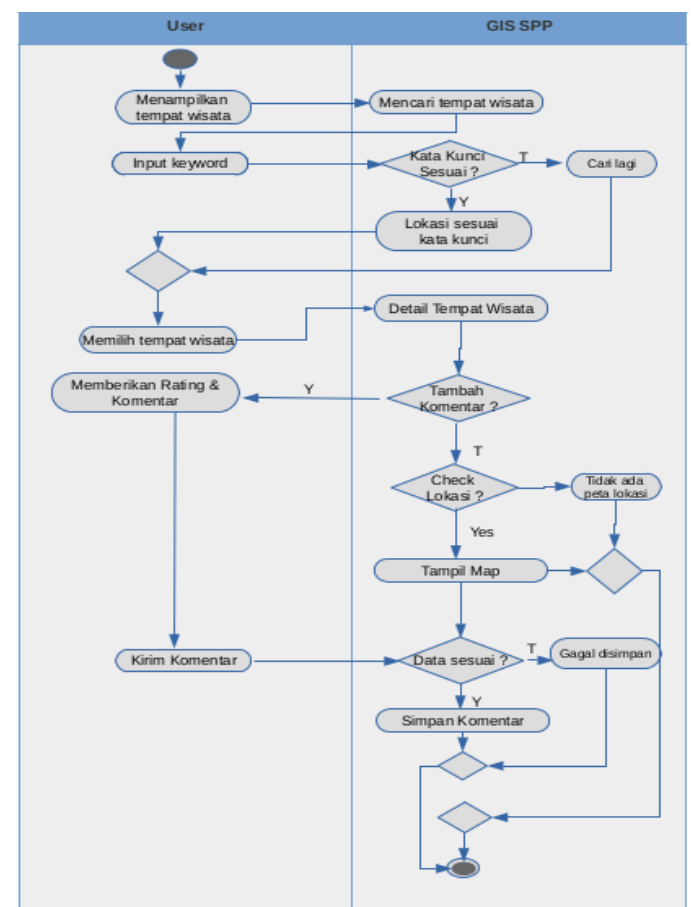

Gambar 4 Activity Diagram

d. Squence Diagram

Squence Diagram menggambarkan bagaimana entitas dan sistem berinteraksi, di mana gambaran umum dari entitas dan sistem yang berinteraksi [15].dapat dilihat di Gambar 5. 


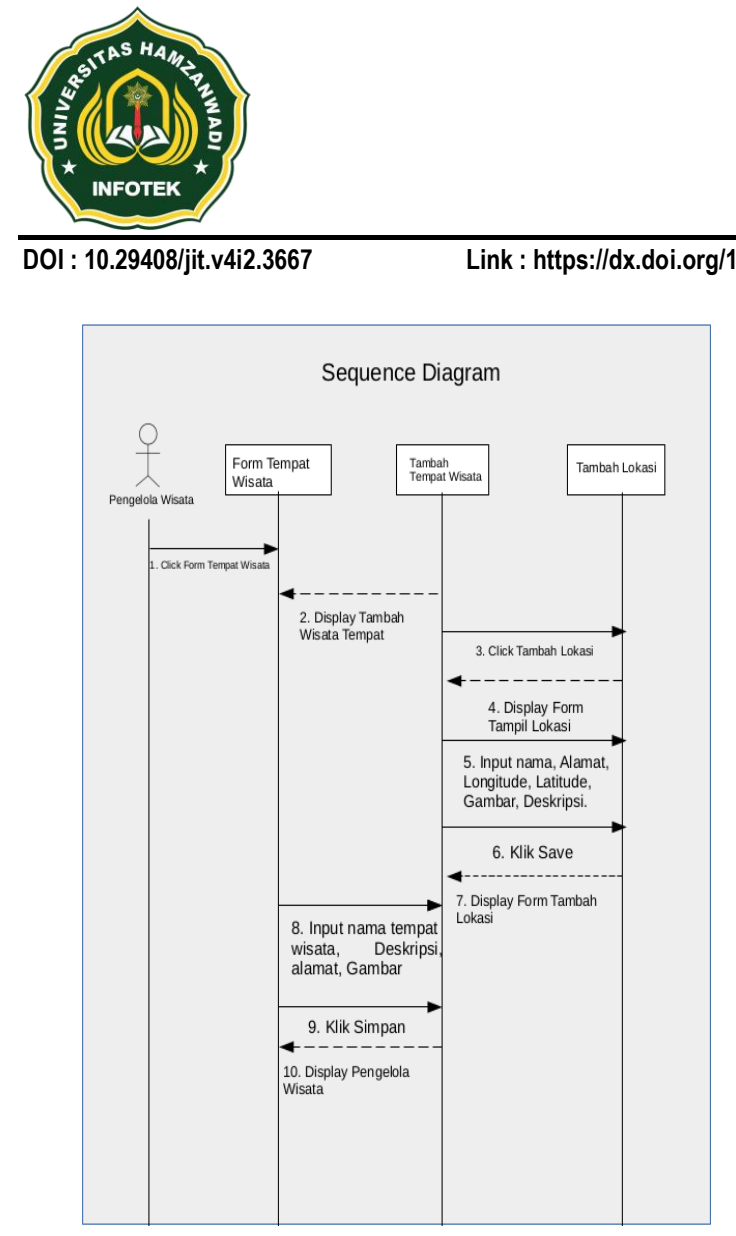

Gambar 5 Squence Diagram

\subsection{Validasi Desain}

Hasil dari validasi desain yang dilakukan langsung oleh pakar sistem informasi dapat dilihat pada Tabel 1 berikut ini:

Tabel 1 Validasi Desain

\begin{tabular}{llll}
\hline No & Pakar & Pengujian & Kesimpulan \\
\hline 1 & Pakar & Cukup & Perbaikan di \\
& Analisis & Baik & $\begin{array}{l}\text { perancangan } \\
\text { database }\end{array}$ \\
& Slstem & & \\
& Informasi & & \\
\hline 2 & Pakar User & Cukup & Perbaikan \\
& Interface & Baik & pada \\
& dan User & & tampilan \\
& Experience & & map dan \\
& & & detail lokasi \\
\hline
\end{tabular}

\subsection{Revisi Desain}

Berdasarkan hasil dari validasi perancangan desain sistem, maka peneliti selanjutnya akan merevisi berdasarkan hasil dari validasi
Infotek : Jurnal Informatika dan Teknologi

Vol. 4 No. 2 Juli 2021

Hal. $259-269$

e-ISSN 2614-8773 perancangan desain sesuai dengan hasil instrument validasi dari pakar sistem informasi dapat dilihat pada Tabel 2.

Tabel 2 Hasil Revisi Desain

\begin{tabular}{llll}
\hline No & Pakar & Pengujian & Kesimpulan \\
\hline 1 & Pakar & Baik & Baik \\
& Analisis & & \\
& Slstem & & \\
& Informasi & & \\
\hline 2 & Pakar User & Baik & Baik \\
& Interface & & \\
& dan User & \\
& Experience & \\
\hline
\end{tabular}

Tabel 2 menunjukkan hasil desain revisi oleh para pakar di bidang analisis dan perancangan sistem informasi serta pakar di bidang user interface dan user experience yang sistemnya desain layak untuk dibangun atau telah memenuhi semua kebutuhan berdasarkan masalah penelitian.

\subsection{Pembuatan Sistem}

Berdasarkan hasil perancangan sistem yang telah diusulkan didapatkan hasil sebuah aplikasi berbasis mobile yang akan diimplementasikan ke pengguna atau user yaitu masyarakat. Tujuan utama dari penelitian ini adalah menciptakan sebuah aplikasi atau sistem informasi geografis tempat wisata yang dapat digunakan untuk mempermudah masyarakat mendapatkan informasi mengenai lokasi tempat wisata. Berikut adalah tampilan aplikasi sistem informasi 
geografis berbasis android untuk wisata pulau Lombok.

\section{a) Tampilan halaman login}

Halaman login aplikasi sebelum masuk ke halaman dashboard. User terlebih dahulu melakukan pendaftaran akun untuk dapat login pada sistem.

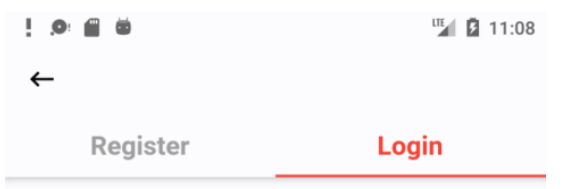

Log in to your account

ஃ Username/Email
๑ Password Q

Forgot Password?

\section{LOGIN}

\section{Gambar 6 Form Login}

b) Halaman Profil

Halaman profil merupakan halaman biodata pengguna atau user, pada halaman profil user atau pengguna bisa mengupdate data profil, halaman profil dapat dilihat pada gambar 7 .

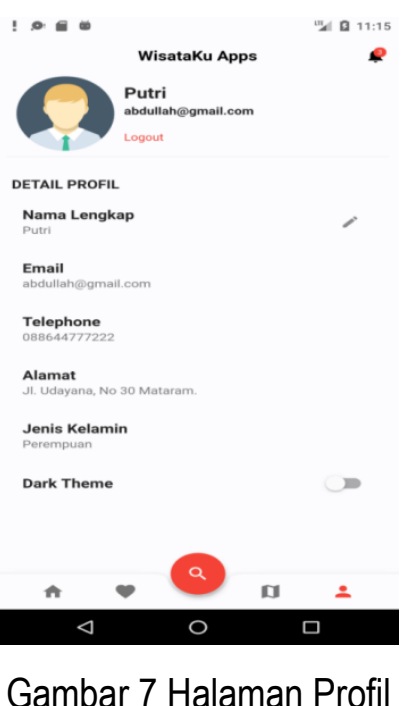

c) Tampilan Peta Lokasi Wisata

Halaman peta lokasi wisata kuliner merupakan halaman informasi lokasi wisata kuliner yang ditampilkan berdasarkan hasil pencarian sistem dalam bentuk peta.

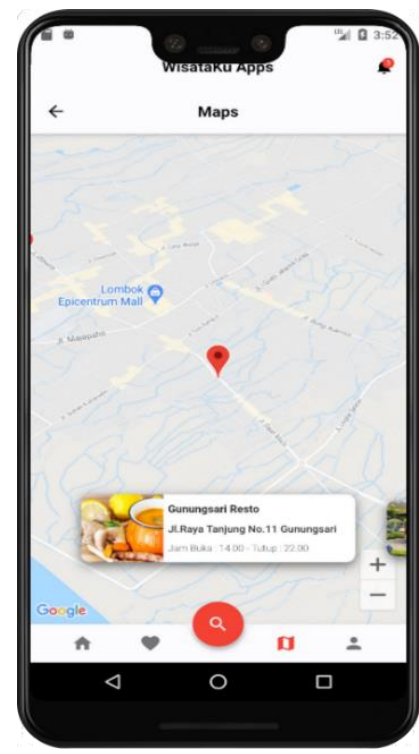

Gambar 8 Tampilan Peta Lokasi Wisata 4.5. Ujicoba Terbatas

Pengujian Aplikasi ini dilakukan dengan menggunakan model ISO / IEC 25010: 2011 yang terdiri dari kesesuaian fungsional, Efisiensi 
Kinerja, Kompatibilitas, Kegunaan, Reliabilitas, Keamanan, Pemeliharaan dan Portabilitas. Pengujian dilakukan dengan jumlah responden sebanyak 15, adapun hasil pengujian sistem dapat dilih

Tabel 3 Hasil Uji Coba

\begin{tabular}{llll}
\hline No & \multicolumn{1}{c}{ Kriteria } & Presentase & Kesimpulan \\
\hline 1 & $\begin{array}{l}\text { Kesesuaian } \\
\text { Fungsional }\end{array}$ & $70,00 \%$ & Baik \\
\hline 2 & Kinerja & $73,33 \%$ & Baik \\
\hline 3 & Kompatibilitas & $71,67 \%$ & Baik \\
\hline 4 & Kegunaan & $71,67 \%$ & Baik \\
\hline 5 & Reliabilitas & $70,00 \%$ & Baik \\
\hline 6 & Keamanan & $73,33 \%$ & Baik \\
\hline 7 & Pemeliharaan & $70,00 \%$ & Baik \\
\hline 8 & Portabilitas & $71,67 \%$ & Baik \\
\hline Rata-rata & $71,45 \%$ & Baik \\
\hline
\end{tabular}

\subsection{Revisi Ujicoba Terbatas}

Berdasarkan Tabel 3 hasil dari ujicoba terbatas dengan rata-rata $71,45 \%$ dengan kriteria "Baik", maka tidak perlu dilakukan revisi ujicoba terbatas.

\subsection{Ujicoba Lapangan}

Ujicoba lapagan dilakukan dengan melibatkan responden sejumlah 35 orang dengan hasil sebagai berikut:

Tabel 4 Hasil Ujicoba Lapangan

\begin{tabular}{llll}
\hline No & \multicolumn{1}{c}{ Kriteria } & Presentase & Kesimpulan \\
\hline 1 & $\begin{array}{l}\text { Kesesuaian } \\
\text { Fungsional }\end{array}$ & $72,14 \%$ & Baik \\
\hline 2 & Kinerja & $73,57 \%$ & Baik \\
\hline 3 & Kompatibilitas & $71,43 \%$ & Baik \\
\hline 4 & Kegunaan & $71,43 \%$ & Baik \\
\hline 5 & Reliabilitas & $72,86 \%$ & Baik \\
\hline 6 & Keamanan & $73,57 \%$ & Baik \\
\hline 7 & Pemeliharaan & $71,43 \%$ & Baik \\
\hline
\end{tabular}

\begin{tabular}{lll}
\hline $8 \quad$ Portabilitas & $72,14 \%$ & Baik \\
\hline Rata-rata & $72,32 \%$ & Baik \\
\hline
\end{tabular}

\subsection{Revisi Ujicoba Lapangan}

Berdasarkan tabel 4, Ujicoba lapangan dengan melibatkan 35 responden menghasilkan presentase rata-rata $72,32 \%$ dengan kriteria "Baik", sehingga tidak perlu dilakukan revisi ujicoba lapangan.

\subsection{Diseminasi dan Implementasi}

Pada bagian ini dilakukan dengan melakukan sosialisasi kepada masyarakat secara luas terkait hasil penelitian yang dilakukan yang berupa sebuah sistem informasi geografis berbasis android untuk wisata pulau Lombok.

\section{Kesimpulan}

Berdasarkan hasil penelitian ini, dapat disimpulkan bahwa tempat wisata di pulau Lombok dapat dibuatkan sebuah sistem informasi geografis menggunakan Android. Dimana fitur dari sistem ini user dapat melihat lokasi tempat wisata, nama tempat wisata, tempat wisata favorit, atupun untuk mencari tempat wisata. Dengan adanya sistem informasi geografis ini diharapkan wisatawan lokal ataupun wisatawan mancanegara dapat terbantu ketika mencari lokasi wisata. Metode penelitian R\&D pada penelitian ini sangat efektif untuk membangun sistem informasi geografis mulai dari perencanaannya hingga implementasi dari 
sistem informasi yang dibangun. Dari hasil pengujian terbatas mendapatkan hasil rata-rata $71,45 \%$ dengan kriteria "BAIK", dan pengujian lapangan dengan mendapatkan hasil dengan rata-rata 72,32\% dengan kriteria "BAIK".

\section{Daftar Pustaka}

[1] B. Prasetyo and U. Trisyanti, "REVOLUSI INDUSTRI 4.0 DAN TANTANGAN PERUBAHAN SOSIAL," Pros. SEMATEKSOS 3 "Strategi Pembang. Nas. MenghadapiRevolusilndustri 4.0," pp. 2227, 2019.

[2] I. Heliany, "Wonderful Digital Tourism Indonesia Dan Peran Revolusi Industri Dalam Menghadapi Era Ekonomi Digital 5.0," Destin. J. Hosp. dan Pariwisata, vol. 1, no. 1, pp. 21-35, 2019, doi: 10.31334/jd.v1i1.551.

[3] Apriani and P. Irfan, "Aplikasi E-Tourism sebagai Pendukung Promosi Pariwisata di Pulau Lombok," Konf. Nas. Sist. Inform., pp. 356-361, 2017.

[4] S. Subhan and R. Umar, "Sistem Informasi Geografis Objek Wisata Kabupaten Lombok Barat Berbasis Web," JSTIE (Jurnal Sarj. Tek. Inform., vol. 7, no. 3, p. 193, 2019, doi: 10.12928/jstie.v7i3.12390.

[5] A. Satriadi and A. Adil, "SISTEM INFORMASI WISATA LOMBOK BERBASIS MOBILE ANDROID," Pros. Semin. Nas. Inform. dan Sist. Inf., pp. 261-262, 2013.

[6] S. Erniwati, A. Subki, S. Program, C. Systems, S. Program, and S. Engineering, "Dsigning Geographic Information System Culinary Tour Lcation In The West Lmbok Region Mobile Based," PILAR Nusa Mandiri, vol. 16, no. 2, pp. 233-240, 2020.

[7] D. M. Mertayasa and A. R. Yambese, "Sistem Informasi Pariwisata Pantai Berbasis Web," Elektron. Sist. Inf. dan Komput., vol. 3, no. 1, pp. 51-61, 2017.
[8] N. K. Ceryna Dewi, I. B. G. Anandita, K. J. Atmaja, and P. W. Aditama, "Rancang Bangun Aplikasi Mobile Siska Berbasis Android," SINTECH (Science Inf. Technol. J., vol. 1, no. 2, pp. 100-107, 2018, doi: 10.31598/sintechjournal.v2i1.291.

[9] A. Sudianto, Nurhidayati, and L. Wijaya, Kerta, "Penerapan Sistem Informasi Geografis Untuk Pemetaan Bengkel Tambal Ban di Kecamatan Selong Kabupaten Lombok Timur," Infotek J. Inform. dan Teknol., vol. 3, no. 1, pp. 51-57, 2020.

[10] H. Kurniawan and M. R. Tanjung, "Sistem Informasi Geografis Objek Wisata Alam di Provinsi Sumatera Utara Berbasis Mobile Android Geographic Information System Object of Natural Tourism in North Sumatra Province Based Mobile Android," J. IIm. SISFOTENIKA, vol. VII, no. 1, pp. 13-24, 2017.

[11] B. Imran and M. M. Efendi, "THE IMPLEMENTATION OF EXTRACTION FEATURE USING GLCM AND BACKPROPAGATION ARTIFICIAL NEURAL NETWORK TO CLASIFY LOMBOK SONGKET WOVEN CLOTH," J. Techno Nusa Mandiri, vol. 17, no. 2, pp. 131-136, 2020.

[12] Riwayatiningsih and $H$. Purnaweni, "Pemanfaatan Sistem Informasi Geografi dalam Pengembangan Pariwisata," Proceeding Biol. Educ. Conf., vol. 14, no. 1, pp. 154-161, 2017.

[13] A. Irawan, M. Risa, M. A. Muttaqien, and A. E. Shinnay, "Perancangan Sistem Informasi Penjualan Pakaian Pada Cv Nonninth Inc Berbasis Online," POSITIF J. Sist. dan Teknol. Inf., vol. 3, no. 2, pp. 74-82, 2017, doi: 10.31961/positif.v3i2.417.

[14] Ermatita, "Analisis Dan Perancangan Sistem Informasi Perpustakaan," J. Sist. Inf., vol. 8, no. 1, pp. 966-977, 2016. 
[15] M. Natsir, "Aplikasi Sistem Informasi Pariwisata Tourism Pada Dki Jakarta Berbasis Android," J. PETIR, vol. 12, no. 1, pp. 18-26, 2019, doi: 10.33322/petir.v12i1.420.

[16] S. M. Sudianto Aris, "Penerapan Sistem
Informasi Geografis (GIS) dalam Pemetaan Kerajinan Kain Tenun dan Gerabah untuk Meningkatkan Potensi Kerajinan di Kabupaten Lombok Timur," Infotek J. Inform. dan Teknol. J. Inform. dan Teknol., vol. 1, no. 2, pp. 64-71, 2018. 